\title{
Meaning, interpretation and unlimited semiosis
}

\author{
Victor Novoselov \\ Department of Philosophy, Novosibirsk State Technical University, Novosibirsk, Russia
}

Email address:

viktor-novoselov@yandex.ru

\section{To cite this article:}

Victor Novoselov. Meaning, Interpretation and Unlimited Semiosis. Social Sciences. Vol. 3, No. 1, 2014, pp. 5-8.

doi: $10.11648 /$ j.ss.20140301.12

\begin{abstract}
This article is devoted the semiotics analysis of concepts «meaning» and «interpretation». On the basis of the analysis the conclusion becomes, that the sign can display a reality only in the course of human activity. Meaning of a sign is a way of its use and interpretation. From the point of view of the theory of interpretants are checked and described conformity, associated with other sign. Thus, the maintenance analysis becomes the cultural-caused operation which is carried out only with physically checked (perceived) products of culture, i.e. with other signs and their mutual correlations. Process unlimited semiotics shows, how signification, constantly correlating one sign with another or with a number of other signs, depicts culture elements.
\end{abstract}

Keywords: Sign, Meaning, Interpretant, Representamen, Denotation, Semiosis, Signification

\section{Introduction}

To understand a sign, it is necessary to interpret it. Sign interpretation is the operation reached at replacement of an initial sign by other sign or a character set. The denotation of any sign, in particular words, non-defined without the reference to a verbal code. Besides no sending to objects can explain a value phenomenon though can help to establish separate denotation of a name. Cardinal property of a sign to transfer denotation - can be shown to concept of interpretation or translation of a sign, i.e. to possibility to present its maintenance other, more explicit, developed signs.

Sign function correlates the given expression to the given maintenance. The maintenance is defined by culture without dependence from that, it will be co-ordinated or not with the given state of peace. «Unicorn» - the same sign, as well as «dog». Possibility to speak about each of these signs is provided with certain index receptions though about "dog" it is possible to speak as about individually existing object, and about "unicorn"- it is impossible. The same concerns for images of a dog and a unicorn. Those images which in semiotics are called as graphic or iconic signs also an essence the expressions correlated with certain maintenance. If they possess properties something (or are similar to something), it something - not object in the world or a state of peace in which it is possible to specify, but the certain structured and analytically organized maintenance. The image a unicorn is not similar to a "real" unicorn; we learn it not thanks to our experience of perception of "real" unicorns but because it has the lines entering into definition of a unicorn, developed by the given culture within the limits of concrete system of maintenances. The same it is possible to tell and in connection with index receptions.

\section{Sign and Representamen}

According to U. Eco, self-sufficiency of a universe of the maintenance given by given culture, explains, why signs can use so that by means of them to tell a lie. «We have the right to speak about sign function when something can be used to lie (and, hence, for working out of ideologies, for creation of works of art and etc.). That is called as a sign (i.e. that for someone acts instead of something other in a certain relation or quality), is that only because we can use a sign for sending to a fictitious state of peace. Even the index can be forged so that it designated event which had no place and actually never generated the prospective sign. Signs can be used to lie because they send to objects or world conditions only mediated. Directly they send only to the certain maintenance. Thus, it is possible to tell that the relation between significant and signify (or between a sign-carrier on value and meant, or between a sign and its value) independently and does not demand presence of a certain designated object as element of the definition. Therefore probably to develop the theory of signification on a basis it is pure intentional semantics. Thus it is impossible to tell that at extensional semantics is not present any function. On the contrary, it 
supervises parity between sign function (a sign-function) and the given state of peace when signs are used to speak or mention about something. But any extensional semantics can be developed (and procedures of the statement or a mention about something can be provided) only because intentional semantics is possible as self-sufficient cultural design (i.e. as a code or system of codes) » [2].

C. S. Pierce enters distinction between a sign and representamen. When he says that uses words «sign» and «representamen» differently, he, obviously, means that sign is some token, something concrete, said - the concrete occurrence of expression used in concrete process of communications and/or reference whereas representamen is the type to which the given code attributes the certain maintenance by means of defined interpretants.

Pierce writes: «Under the sign I understand everything that in any way transfers any certain notion about a certain object as we know such transmitters of thought under this name. And here I begin with this familiar idea and I make as it is possible the best analysis of that is essential to a sign, and [then] I define representamen as all that approaches under this analysis... In particular, all signs transfer concepts to human consciousness's; but I do not see the reason why it should be true for all representamen» [3].

Eco makes comments on this fragment as the assumption of distinction between the signification theory and the communications theory. Representamens are typical expressions, correlated in the given culture with that or other typical maintenance, without dependence from, whether they are used for the valid communications someone with someone.

In this sense value is, in the primary understanding, sign transfer in other system of signs, and value of the given sign is that sign, in which given sign should be translated. Thus, interpretation by means interpretants is a way by which the sign is demonstrated (is shown) as denotation.

Interpretant is that the sign generates in the interpreter, but as interpreter presence is not included an essential part into definition interpretant, this last should be considered first of all as interpretant, opening in correct understanding of the sign and usually named the meaning of $a$ sign.

So, differing as formal objects of various semiotics approaches and as considered from the various points of view, value and interpretant is, as a matter of fact, same as it is impossible to define value differently, than as a number interpretants.

However, underlines Eco, interpretant is not only value of the term, but also the result of conclusion deduced from certain parcels. Whether we should believe, what interpretant has wider and more difficult sense, than meaning? Meaning of a certain statement, as well as it interpretant, do not settle all possibilities of the given statement to be transformed to other statements [2].

\section{Meaning and Signification}

So, meaning somehow follows from a parcel. Even more generalizing, it is possible to tell that value is everything that semantics it is meant a sign. In other words, according to the Pierce the meaning of a sign comprises all those texts into which the given sign can be inserted in the rudimentary form. The sign is a text matrix.

However in that case the concept «the meaning» appears too wide. It is applied not on separate terms, and to parcels and conclusions. Differently, the theory of value and interpretants concerns not only conclusions, but also to separate terms, and - in the light of this theory - the maintenance of the separate term becomes something similar to the encyclopedia.

Thus, the symbol denotes something individual and signifies a certain property, what property and is a general meaning. Distinction between a denoting and signifying is connected with distinction between extensional and intentional, between width and depth, or between denotation and meaning, i.e. between sending, reference to something and signifying of something. The concept "depth" is connected with concept "information" which is a measure predicate.

Signs of the given term include all depth of other term, substantial definiteness of the first term thereby increases. The term can have both necessary, and casual ("accidental") signs, these signs make substantive depth of the term. In this sense depth of the term (or it intentional) is the sum intentional or semantic signs (dung) which characterize its maintenance [3].

This set of signs (or dungs) should expand in process of growth of our knowledge of objects. Sign, like a magnet, draws to itself all those new lines and signs which process of knowledge to it attributes. As writes the Pierce: «Each symbol is something live, in the most direct, completely not figurative sense. The symbol body changes slowly, but its value inevitably grows, incorporating new elements and rejecting old» [3]. Thus, the term in itself is the article of the encyclopedia containing all those characteristics which it gets with each new general statement.

The term is a rudimentary statement, because it - empty the statement form.

Thus, any sign interprets other sign, and the basic condition of semiotics $\sim$ it is sending from one sign to another, infinite regress. At such approach everyone interpretant the given sign, being in turn also a sign, becomes time metasemiotics construct, acting (and only in this case) in quality explains no to the relation to interpreted explicator, - and, in turn, can be interpreted by other sign which will act in relation to it in quality interpretant.

The infinity of it of some, however, could make the semantic encyclopedia impracticable, again and again depriving of attempt of the semantic analysis of any hope of successful end. But, according to Eco, the encyclopedia has a logic limit, it cannot be infinite: this limit - a discourse universe [2].

The unlimited universe would capture all area logically possible. Our discourse seldom corresponds with this unlimited universe: we mean either physically possible, or 
historically existing, or the world of any art fiction, or still any limited universe.

The concept «a discourse universe» along with concept «the possible world» connects a problem semantic representation with a problem of contextual preferences and opens interesting prospects in the field of the modern theory of sign systems.

How the sign can display a reality concerning an external world if by the nature of things it is not capable of it? How probably to connect a sign with object if to distinguish object, it is necessary to have former experience of its perception, and the sign does not provide neither acquaintances, nor object recognitions? It is possible only in the course of activity. Value of a symbol consists in a set of the actions, called to make certain notable effects.

Sign, causing a number of direct reactions (power interpretant), gradually creates a certain habit, a certain regularity of behavior at the interpreter (or the user) this sign Differently, the parity between meaning and representamen gets the form of the law; on the other hand, to understand a sign means to understand the nobility that it is necessary to do to create such concrete situation in which it is possible to find sensual experience of that object to which sends the given sign.

The sign can make interpretants two kinds: emotional interpretant and the power interpretant. Thus power reaction itself does not demand interpretation; more likely she creates (obviously, at the further repetitions) a new habit. In other words having apprehended a number of signs, we change our behavior, our activity in the world - forever or for a while. In this point unlimited semiotic stops (stops: a stop not limited in time, chronological sense because all our ordinary life is penetrated by such changes of habits). The exchange of signs leads to experience change; absent a link between semiotic and a physical reality as practical action it is found.

To understand a sign as a rule (which speaks by means of a number interpretant of the given sign) is means to get a habit to operate according to the instruction proceeding from the given sign [3, 4].

Thus, the action repeatedly made in reply to the given sign, becomes, in turn, a new sign, representamen of the law, interpreting the first sign both to beginning new and never-ending process of interpretation.

The circle considered in this prospect semiotic becomes isolated during each instant - and does become isolated never. The system of semiotics (sign, code) systems which can seem the unreal world of culture idealistically separated from the validity actually induces people to influence the world; and everyone such reformative the world influence, in turn, always and itself turns to new signs and begins new process of semiotic $[9,10]$.

Last time many theorists of semiotics have refused attempts to study denotation, having substituted instead of this concept "reference". The reason consists that if you want to distinguish accurately the maintenance of expression and possible object of this expression you risk to get in mentalism or psychologism. The expression maintenance then will appear that "wanders" in a head of the interpreter which has received (i.e. apprehended) the given expression. Just because it is impossible to follow similar "wandering", some theorists have preferred not to deal with denotation. But unique alternatives were or value replacement with a corresponding state of peace (it is strict extensional interpretation according to «the new theory of reference»), or value data to the behavior caused by a sign (according to late C. Morris) $[1,7,8]$. However, as there are the expressions which denotation in any way cannot be seen through observable, the behavior criterion is represented rather unsatisfactory $[4,5]$.

In researches on structural and componential semantics the method of purely metalinguistic description of the maintenance has been developed as structured network opposed units which, being selectively and are hierarchically organized, form a componential spectrum of the given subject of the description. But whether these components only are theoretical construction? Whether certainly their number (whether they form final set)? Whether are components of verbal expression also, in turn, verbal expressions? The concept of interpretant resolves all these problems.

If representamen sends to the given element of the maintenance, and this element consists of smaller and "more elementary" units it is possible to understand all only by means of mediating signs (signs-intermediaries).

In a context of the general semiotics theory (which considers not only verbal expressions, but any kind's signification, and also the relation between various systems) the componential analysis of the verbal term should not limit circle of its interpretant to only one linguistic terms.

The semantic theory can analyze the expression maintenance in the various ways:

a) Looking for equivalent expression in other semiotics substance (a word / a dog / - the image of a dog);

b) Looking for all equivalent expressions in the same semiotics system (synonym);

c) Specifying in possibility of mutual transfer between the different codes concerning the same semiotics substance (transfer from one language on another);

d) Replacing the given expression by more analytical definition;

e) Listing all emotional connotations, habitually connected with the given expression in the given culture and consequently in a special way coded (so, / the lion / has connotations / ferocity / and/rage/).

But no semantic analysis can be full if he does not analyze verbal expressions by means of visual, subject and behavioral interpretants (and on the contrary).

\section{Conclusions}

From the point of view of U. Eco, the concept of interpretant rescues a category "maintenance" (as well as a category " denotation") from transformation in imperceptible Plato's abstraction or in not followed the 
mental certificate. As interpretant it is identified with any coded and realized property of the maintenance, and these properties can be identified only in the form of other signs (i.e. others representamen), maintenance elements become something physically checked. Each given culture in any sphere of the ability to live finds out the settled parities (correlation) between different representamen (or expressions) so each of them in the turn becomes interpretant another.

Interpretant is not only that is identified with elementary semantic components. Actually, concept of interpretant is much richer. Even on manufacture of conclusions on which any phrase or the whole book moves us, it is necessary to consider those efforts as interpretation of initial semiotics stimulus.

From the point of view of the theory of signification are checked and described conformity, associated, on a consensus, with other sign. Thus, the maintenance analysis becomes the cultural-caused operation which is carried out only with physically checked (perceived) products of culture, i.e. with other signs and their mutual correlations. Process unlimited semiosis shows to us as signification, constantly correlating one sign to another or with a number of other signs, depicts culture elements, never allowing to touch them is direct, but doing their accessible through intermediary of other elements. So, we are never obliged to replace an element of culture with something that there is no semiotics essence, and no element of culture should be we explain through any Plato's mental or subject essence. Semiosis explains itself: This constant circular motion is a normal condition of signification, and it (this circular motion) even allows to use signs to speak about subjects and world conditions on a course of processes of communications.

\section{References}

[1] Моррис Ч.У. Основания теории знаков. - Семиотика. M., 1983.

[2] Эко У. Отсутствующая структура. Введение в семиологию. Спб., 2006.

[3] Пирс, Ч.С. Избранные философские произведения. - М.: «Логос», 2000.

[4] Davidson D. Truth and Meaning. - Synthese, 17 (1967). Pp. 304-323.

[5] Davidson D. Radical Interpretation. — Dialectica, 27 (1973). Pp. 313-327.

[6] Lewis D. Counterfactuals. Cambridge Mass., 1973

[7] Putnam H. Meaning and Reference. - Journal of Philosophy, 1973, v.70. P. 707.

[8] Putnam H. Representation and Reality. Cambridge Mass., 1988.

[9] Quine W. V. Word and Object. Cambridge Mass. - N.Y., 1960.

[10] Russel B. On Denoting //The Philosophy of Language (3 edition), A. P. Martinich (ed.). - Oxford University Press, 1996. P.112 - 126 .

[11] Victor Novoselov. Sign and Reality, Social Sciences. Vol. 1, No.1,2012,pp.1-6

http://www.sciencepublishinggroup.com/journal/archive.asp $\mathrm{x}$ ?journalid $=202$ \&issueid $=2020101$

[12] Victor Novoselov. The Problem of a Signs and World Objects Parity, International Journal of Economy, Management and Social Sciences, Vol 2 - No 12, 2013. pp. 1002-1007 : http://tijournals.com/index.php?action=showinpress\&jid $=6$ \&pid $=44$ 